\title{
The Disenchantment of Nonsense: Understanding Wittgenstein's Tractatus
}

\author{
Leo K. C. Cheung, Hong Kong Baptist University
}

More than eight decades after its publication, commentators still have not come to an agreement on how the Tractatus should be understood. This may seem strange given that Wittgenstein stated very clearly ${ }^{1}$ that he aimed to draw a limit to thought by drawing one to language, so that philosophical utterances (i.e., problems, questions and propositions) can be recognised as nonsensical, allowing one to see the world aright and be content to silently pass over what cannot be said. However, he also seems to have given the book a self-annihilating character when he states in TLP 6.54, "[m]y propositions serve as elucidations in the following way: anyone who understands me eventually recognises them as nonsensical". ${ }^{2}$ The difficulty is one of understanding the book as a coherent whole and then to see what it is really about. In this paper, I shall first argue against a prominent interpretation of the Tractatus - namely, the resolute reading - and then suggest a way of understanding the Tractatus correctly.

The resolute reading ${ }^{3}$ is said to be a correct way of reading the Tractatus, and treats the declaration of nonsense in TLP 6.54 seriously.

1. For example, in the preface and in entries like TLP 4.003, 6.522, 6.53-6.54 and 7.

2. Pears and McGuinness' translation is used in this paper; unless stated otherwise, where the Odgen translation is used.

3. The resolute reading has also been called "the therapeutic reading" by Marie McGinn (1999) and by the editors of The New Wittgenstein in their "Introduction" (Crary and Read 2000, 1) "the post-modernist interpretation" by Peter Hacker (2000), and so on. The currently popular name seems to be "the resolute reading"; see Sullivan $(2002,43)$. I am following the current here. See also (Conant and Diamond 2004, 87, footnote 1). 
It was first suggested by Cora Diamond, and then followed and further elucidated by James Conant and many others. ${ }^{4}$ Its programmatic nature allows a large number of variants. ${ }^{5}$ Among them, Diamond and Conant's versions are the most influential, and close enough to be seen as a unified interpretation. I therefore take the Diamond-Conant version as the major representative of the resolute reading.

The resolute reading is often contrasted with what Diamond and Conant call "the standard interpretations", and is seen as being right exactly where the standard interpretations go wrong. It is not clear what the interpretations they regard as standard are. Nevertheless, G. E. M. Anscombe and Peter Hacker are certainly taken to be two major representative proponents of the standard interpretations, as their views have been chosen and criticised in such contexts. ${ }^{6}$ According to Diamond and Conant, the standard interpretations hold that the nonsensical sentences ${ }^{7}$ referred to in TLP 6.54 are capable of showing unsayable insights (or "truth"), and that the recognition is achieved by employing the theory of meaning specifying the conditions of sense advanced in the Tractatus. ${ }^{8}$ In Hacker's version, nonsense is caused by using signs in contravention of logical syntax, and the Tractarian theory of meaning serves to detect the contravention, and hence too the nonsense. ${ }^{9}$

What makes a reading resolute, according to Diamond and Conant, is having two basic features that flatly reject the alleged positions of the standard interpretations. The first basic feature is that nonsense can neither show nor say anything. The second basic feature is that the Tractatus does not advance any theory of meaning specifying the conditions of senses ${ }^{10}$ nor does it hold that there is such a thing as using signs in contravention, or violation, of logical syntax that must

4. See Diamond (1991b, 1997, 2001), Conant (1989, 2000, 2001), Goldfarb (1997) and Ricketts (1996). The authors of the articles in Crary and Read (2000), except Hacker, are all proponents of the resolute reading.

5. See Conant and Diamond (2004, 47-48) and Conant (2007, 47, footnote 108).

6. For example, Hacker's view has been criticised at length in Diamond (1991b, 2005 ) and in Conant $(2000,2001,2002)$. Howard Mounce is also taken to be a representative proponent of the standard interpretations by Read and Deans (2003).

7. The German word "Satz" in the Tractatus may mean proposition or sentence. I use the translation "sentence" whenever the discussion is about a nonsensical Satz.

8. See Conant $(2007,44)$.

9. See Conant $(2001,39 ; 2002,393-394)$.

10. See Conant and Diamond (2004, 47-48). 
produce nonsense. ${ }^{11}$ There may be significant differences among different versions of the resolute reading, but the fact that they are resolute is determined by sharing these two basic features. ${ }^{12}$ The resolute reading should be seen as a programme. ${ }^{13}$ It draws from the two basic features the conclusion that any suggestions such as the standard interpretations to seeing the Tractatus as attempting to show unsayable insights are unacceptable. It is then natural for Diamond and Conant to characterise the standard interpretations via a logical distinction between different kinds of nonsense. For Conant, the distinction is one between mere nonsense, or what is "simply unintelligible", and substantial nonsense, or what is "composed of intelligible ingredients combined in an illegitimate way - it expresses a logically incoherent thought" (Conant 2000, 176). ${ }^{14}$ Instances of substantial

11. Conant holds that the only way of talking about the contravention of logical syntax is "cross-category equivocation - the result of allowing different occurrences of the same sign to symbolize items of a different logical category" (Conant 2001, 44, 46), which may or may not produce nonsense.

12. In a recent paper, Conant $(2007,42-47)$ characterises the resolute reading in a slightly different way. He thinks that the resolute reading rejects the idea that Wittgenstein is to call upon his readers to grasp a theory of meaningfulness (i.e., a theory that specifies the conditions under which sentences make sense and those under which they do not) advanced in the Tractatus. He then emphasizes three corollaries of this point. The first corollary is that the resolute reading rejects any commitment to an ineffable theory or doctrine. The second one is the rejection of the idea that there are logically distinct kinds of nonsense. The third one is that the resolute reading holds that the forms of logical notation employed by the author of the Tractatus must be elucidatory instruments, and their employment does not require commitment to any particular philosophical theses. With the exception of the last corollary (which is new), this way of characterising the resolute reading is not significantly different from the characterisation in (Conant and Diamond 2004). (This may need the quantification that, in the new characterisation, there is the problem that it is not clear how the latter three points follow from the first one as corollaries.)

13. The resolute reading allows numerous variants. Read and Deans $(2003,251)$ have classified them into "strong" and "weak" versions based on their different views on the nature of the frame. While agreeing that there are different versions of resolutism, Conant (2007, 131, footnote 101), however, does not agree with Read and Deans. Instead of classifying different versions of the resolute reading, Conant thinks that some of their criteria seem to be intended to sort readers into those who are mildly and those who are zealously Mono-Wittgensteinianism (where mild and zealous MonoWittgensteinianism are different views concerning the relationship between the early and the later Wittgenstein). For his own view of how resolutisms can be very different from one another, see, for example, Conant (2007, 47-66); especially how he thinks resolutists can see the rungs of the ladder, which he identifies with a list of sentences (Conant 2007, 50-51), with different orders of dialectical steps and different orders of discovery (Conant 2007, 53).

14. Or, mere nonsense is defined as "a string composed of signs in which no symbol can be perceived, and which hence has no discernible logical syntax", and substantial 
nonsense are, so to speak, "logically determinate forms of nonsense" (Conant 2007, 44). To think, as Hacker allegedly does, that nonsense caused by the contravention of logical syntax can show unsayable insights is to adopt substantial nonsense, while the purpose of the Tractatus is exactly to liberate one from the grip of substantial nonsense. ${ }^{15}$ Diamond famously accused the standard interpretations of reading Wittgenstein as "chickening out". ${ }^{16}$

As a proposal to read the Tractatus in the right way, the resolute reading needs to specify how it should be read and what it is really about. So, besides the two basic features, the Diamond-Conant version also holds two other major ideas. One idea is that all the sentences of the Tractatus, except those few serving as "the frame" that instructs how the book is to be read, are nonsensical. The frame includes the preface (focusing only on "the whole sense" and "the aim" of the book) and TLP 6.54-7 (and, depending on the particular view of a resolutist, it may include more or different or any entries ${ }^{17}$ ). The non-frame sentences are all nonsensical and thus can neither show nor say anything. ${ }^{18}$ Diamond and Conant then appear to think that the Tractatus is not trying to help anyone to see any unsayable insights. This leads to another major idea that the aim of the Tractatus is merely to liberate nonsense utterers from nonsense, and that this is to be achieved by the non-frame sentences serving as elucidations. The non-frame sentences, admittedly being nonsensical, can still elucidate, as TLP 6.54 says, so that one can see the world aright after using and then discarding them.

nonsense as "a proposition composed of signs which symbolize, but which has a logically flawed syntax due to a clash in the logical category of its symbols" (Conant 2000, 191). For Diamond (2001), the distinction is one between sentences that are mere nonsense and sentences that "count as nonsense but do manage to gesture towards those things that cannot be put into plain words", or between sentences that are mere nonsense and "sentences that are nonsense but would mean [what cannot be spoken about] if there could count as sense" (150).

15. See, for example, "the sort of reading of Wittgenstein I have in mind might be put as follows: Wittgenstein seeks to show that the utterances of metaphysicians are nonsense by exposing them to be logically (or conceptually) flawed, where these flaws are to be traced to specifiable infringements upon the conditions of meaningful discourse ... these infringements arise through violations of 'the principles of logical syntax" " (Conant 2001, 13). See also Conant $(2001,14)$.

16. See Diamond (1991a, 181).

17. See endnote 102 in Conant $(2000,216-7)$. Read and Deans (2003) take the Tractatus as operating at different levels and, for what they call "the strong version" of resolutism, the frame is also seen in the end as another expression of the impulse towards metaphysics and is to be surmounted (249-251).

18. See Diamond (1991b, 181, 184). 
They elucidate (which is to be distinguished from showing) by first leading the readers into taking nonsense for sense so as to liberating them from nonsense. ${ }^{19}$ In such a dialectical process, the sentences including those apparently intelligible but in fact nonsensical "distinctions" and "theses", like anything appearing to be a theory of meaning and the distinction between showing and saying - are "ladder rungs" to be genuinely discarded once used. ${ }^{20}$

I shall argue that the first basic feature does not characterise a resolute reading. To think so is based on a serious misunderstanding of the standard interpretations, at least of those held by Anscombe and Hacker. The standard interpretations do not hold that nonsense can show anything, nor do they adopt the notion of substantial nonsense. To see this, consider first what Diamond means by reading Wittgenstein as not chickening out and then why she thinks the standard interpretations are reading him as chickening out.

To read Wittgenstein himself as not chickening out is to say that it is not, not really, his view that there are features of reality that cannot be put into words but show themselves. What is his view is that that way of talking may be useful or even for a time essential, but it is in the end to be let go of and honestly taken to be real nonsense, plain nonsense, which we are not in the end to think of as corresponding to an ineffable truth. (Diamond 1991a, 181)

What is genuinely throwing away the ladder is that ${ }^{21}$

we ... have got past the attempt to represent to ourselves something in reality, the possibility of what a sentence says being so, as not sayable but shown by the sentence. (Diamond 1991a, 184; my emphasis)

The phrase "by the sentence" here suggests that, according to a chickening out interpretation, what shows or "gestures at" an unsayable truth is the relevant nonsensical sentence itself. What Conant calls "the ineffability interpretation", allegedly shared by the standard

19. See Diamond $(2001,160)$.

20. See ibid.

21. See Diamond (1991b, 181-182). Diamond (1991b, 194) also says, "[t]o chicken out is to pretend to throw away the ladder while standing firmly, or as firmly as one can, on it". 
interpretations, is also chickening out. The ineffability interpretation holds that Wittgenstein aspires to show ineffable truth by means of nonsense $\mathrm{e}^{22}$ or that "the sentences in question are revealed as simultaneously meaningless yet able to convey something determinate" (Conant 2007, 44). Do Anscombe and Hacker hold that the same nonsensical Tractarian sentence shows an ineffable truth?

Let me consider Diamond's criticism of the following passage by Anscombe on the Tractatus' view of things that cannot be said but shown:

Can we ... draw a distinction ... between things that would be true if they could be said and those that would be false if they could be said? It is impossible to speak like this of attempted contradictions of what is "shewn" . . . whereas " "someone' is not the name of someone" is intended to say something "quite correct" . . we must say concerning " "someone' is the name of someone" that what such a proposition intends is not merely not correct, but quite incoherent and confused; the demonstration that this is so completely destroys the idea that there is anything at all behind the would-be statement. (Anscombe 1971, 162)

\section{Diamond sees from this passage that:}

[Anscombe holds that] there are some sentences which are nonsense but which would say something true if what they are an attempt to say could be said. The unsayability of what they attempt to say precludes its being said, but we can nevertheless grasp what they attempt to say ... So she works with the contrast between nonsense-sentences that have something, something true but unsayable, behind them, and those that have nothing but confusion behind them. (Diamond 2001, 158)

For Diamond, the distinction that Anscombe is making here is a logical one between two different kinds of nonsense, unlike the external distinction between nonsensical sentences serving different roles for the imagination that Diamond is happy to make. ${ }^{23}$ Anscombe's interpretation is chickening out.

22. Conant (2000, 199, footnote 11, my emphasis) says, "I am using the word 'show'... not in the sense which the Tractatus itself reserves for this term (which, as we shall see, is not applicable to nonsense), but rather (as it is often used by proponents of the ineffability interpretation) to refer to the activity of 'hinting' or 'gesturing' at ineffable truths by means of nonsense."

23. See Diamond (2001, 158-159). 
Diamond, however, cannot draw such a conclusion. She has overlooked what Anscombe writes immediately before the above passage:

an important part is played in the Tractatus by the things which, though they cannot be "said", are yet "shewn" or "displayed". That is to say: it would be right to call them "true" if, per impossible, they could be said; in fact they cannot be called true, since they cannot be said, but "can be shewn", or "are exhibited", in the propositions saying the various things that can be said. (Anscombe 1971, 162; emphasis in the last phrase is mine)

With this passage, Anscombe's view becomes very clear: what cannot be said but can be shown is not shown by the relevant nonsensical sentences, but rather by "the propositions saying the various things that can be said", i.e., by significant propositions saying something else. The distinction that she is trying to make in the first passage is between a nonsensical sentence, say " $p$ ", which is an attempt to say what can only be shown by a significant proposition, say " $q$ ", and the nonsensical sentence " $\sim p$ ", which is an attempt to say what cannot be shown by any proposition. Whatever significance such distinction could have, Anscombe is clearly not committing to the view that there is a logical distinction between the nonsensicality of " $p$ " and " $\sim p$ ". Also, she does not hold that a nonsensical sentence, which is an attempt to say an unsayable truth, can show or gesture at the unsayable truth. Accordingly, she need not make any logical distinction between different kinds of nonsense. One cannot ascribe to her interpretation the notion of substantial nonsense.

Admittedly, there are commentators who think Wittgenstein takes nonsensical pseudo-propositions to be able to show something that cannot be said. Max Black is an example. ${ }^{24}$ Black suggests that a large number of remarks referred to in TLP 6.54-7 belong to "logical syntax" or philosophical grammar. They are "formal statements, 'showing' something that can be shown" (Black 1964, 381). But, ironically, it is Hacker who points out in his Insight and Illusion that Black's move is incorrect. For Hacker (1986, 25-26), " 'formal statements' ... neither say nor show anything. They do violate the rules of logical syntax, for they wrongly employ formal concepts ... the 'formal' statements that use them are nonsense". Hacker clearly does not take Wittgenstein as holding that a nonsensical sentence can show

24. See Black (1964: 378-386).

(C) 2008 The Author. Journal compilation (C) 2008 Blackwell Publishing Ltd. 
or gesture at any unsayable truth. Indeed, what the nonsensical sentences are attempting to say can neither be said nor shown by them, but is shown by significant propositions:

Philosophers try to say what can only be shown, and what they say, being nonsense, does not even show what they try to say. Nevertheless, even within the range of philosophical, covert nonsense we can distinguish, as we shall see, between what might (somewhat confusingly) be called illuminating nonsense and misleading nonsense. Illuminating nonsense will guide the attentive reader to apprehend what is shown by other propositions which do not purport to be philosophical. (Hacker 1986, 18; my emphasis)

Hacker does not make any logical distinction between different kinds of nonsense. His distinction between illuminating nonsense and misleading nonsense is not a logical one. (Even Conant would agree with him. ${ }^{25}$ ) It is wrong to ascribe the notion of substantial nonsense to his interpretation. Hacker repeats the same points again and again. For instance, he writes in his "Was He Trying to Whistle It?", ${ }^{26}$

Wittgenstein's own propositions ... are, by the light of the Tractatus, nonsensical pseudo-propositions. They show nothing at all. The propositions that are held to show the ineffable truths which the Tractatus seems to be trying to say are not the pseudo-propositions but well-formed propositions (including the senseless propositions of logic). (Hacker 2000, 356)

It is very surprising that although Hacker has already made his points very clear, he was still chosen as a major representative of the standard interpretations. ${ }^{27}$

Diamond and Conant have therefore seriously misunderstood the standard interpretations, and this is very widespread among many commentators, including the resolutists and some of their opponents. ${ }^{28}$

25. See Conant (2000, 195-196).

26. In another paper "Philosophy", while interpreting the Tractatus, Hacker $(2001,326)$ writes, "[t]o be sure, what philosophers were trying to say by means of the pseudopropositions of philosophy is shown by well-formed sentences with a sense".

27. In response to the criticisms from Read and Deans (2003), Mounce denies that he has ever claimed that the propositions of the Tractatus show something in themselves. He makes very clearly the point shared by the standard interpretations that "[the Tractarian propositions' ] purpose ... is to direct our attention to what shows itself in the legitimate use of signs" (Mounce 2003, 269-270).

28. An example of the resolutists is Michael Kremer. This can be seen from his criticism of Hacker and Anscombe: "they stick to the letter of the doctrine that Wittgenstein's teaching cannot be said, and his pronouncements are nonsense, but hold 
Locating the misunderstanding not only helps to rectify the mistake and remove the widespread influence; it also helps one appreciate the Tractatus' view that what the nonsensical Tractarian sentences appear to be saying can be shown not by any nonsensical sentences but by significant propositions saying something else. The misunderstanding also causes the resolutists' to mistakenly think that the first basic feature is a sufficiently novel point of the resolute reading. In fact, the first basic feature does not even characterise a resolute reading.

The second basic feature, as conceived by Diamond and Conant, is a polemic against the standard interpretations, especially Hacker's version. They think that Hacker characterises substantial nonsense via the contravention of logical syntax, and holds that the recognition of nonsense requires the employment of the theory of meaning advanced in the Tractatus. ${ }^{29}$ They also use TLP 5.4733 as their major textual evidence for the second basic feature. However, the standard interpretations, as pointed out already, do not adopt the notion of substantial nonsense. Hacker does hold that there is for the Tractatus such a thing as using signs in contravention of logical syntax. But he need not, and does not, hold that the recognition of nonsense needs a theory of meaning specifying the conditions of sense, nor does he think the Tractatus advances any such theory. For one can recognise nonsense by mastering the rules of logical syntax without employing any theory of meaning. ${ }^{30}$ Two questions are left to be considered here. First, would the notion of the contravention of logical syntax considered by Diamond and Conant be adopted by the Tractatus? Second, does their major textual evidence TLP 5.4733 prove that for the Tractatus there is no such a thing as using signs in contravention of logical syntax?

\footnotetext{
onto to the opposite thought as well, disguising this by saying that while his pronouncements do not say anything, do not express any thought, and are not true, they convey what he means or intends, and this meaning or intention is quite correct" (Kremer 2001, 45). An example of the non-resolutists is Marie McGinn. She also takes it as the problematic idea of what she calls "the metaphysical reading", i.e., what is called "the standard interpretations" here, that "ineffable truths about reality [are] conveyed through nonsense-sentences" (McGinn 1999, 495-496).

29. See, for example, Diamond (2005, 78-9).

30. See Hacker $(2003,11-13)$.
} 
Diamond and Conant think that holding that there is contravention of logical syntax means adopting the substantial conception of nonsense. ${ }^{31}$ They in effect characterise substantial nonsense in terms of the illegitimate or logically flawed combination of intelligible ingredients. ${ }^{32}$ For Conant, legitimate ingredients are symbols or symbolising signs, and illegitimate combination means a clash in the logical categories of the symbols which produces substantial nonsense. ${ }^{33}$ When Conant talks about the Tractatus' refusal to accept any such thing as the contravention of logical syntax, he is referring to the rules of logical syntax as what govern the combination of symbols. The Tractatus, however, takes the rules of logical syntax as governing not the use of symbols but signs. ${ }^{34}$ This can be seen from, among others, TLP 3.325 ("a sign-language that is governed by . . logical syntax"), TLP 3.33$3.331^{35}$ and TLP 6.126 (where the rules that deal with signs are clearly rules of logical syntax). The rules of logical syntax exclude nonsensical combinations of signs (i.e., they do not symbolize, and make no contribution to the expression of sense). Besides the textual evidence, it is perhaps more important to understand the notion of logical syntax as what excludes nonsensical combinations of signs.

For the Tractatus, a sign signifying with two different modes of signification in two propositional contexts becomes two different symbols. ${ }^{36}$ In the example in TLP 3.323 , the same sign "green" in the proposition "Green is green" signifies with two different modes of signification when it is used as the sign of a proper name (the first word) and as the sign of an adjective (the last word) in the proposition. It is the sign of two different symbols. The mode of signification of a sign also determines its logico-syntactic form (TLP 3.327), or syntactic-combinatorial possibilities (TLP 2.032-2.033). For example,

31. I of course agree with Diamond and Conant, and Hacker would also agree, that no one is talking about the notion of the contravention of logical syntax as cross-category equivocation, which may or may not produce nonsense, here.

32. See Conant $(2000,176,191)$.

33. See Conant $(2001,14)$.

34. It is surprising that Conant $(2001,42)$ thinks the Tractatus takes the rules of logical syntax as governing neither the combination of signs nor that of symbols: "[L]ogical syntax is concerned neither with the proscription of combinations of signs nor with the proscription of combinations of symbols".

35. The rules of logical syntax established in a way without mentioning meanings (Bedeutungen) in TLP 3.33-3.331 are clearly rules of signs.

36. Of course, a sign can be used in different ways, just as the cube in TLP 5.5423 can be perceived in different ways as different complexes. 
the first word in "Green is green" is a sign signifying with the mode of signification of (and thus symbolizes as) a certain proper name, whose function is to denote a person. The last word in "Green is green" is the same sign but is combined with other signs in a different way, i.e., having a different logical form, and thus symbolizes as an adjective. How a sign signifies is governed by the rules of logical syntax (TLP 3.322, 3.326 and 3.334).

A sign used in accordance with certain rules of logical syntax, i.e., with a certain mode of signification, becomes a symbol and is thus capable of signifying. A sign used in contravention of certain rules of logical syntax fails to become a symbol, i.e., does not symbolize, and is incapable of signifying. For example, the sign "identical" is used in accordance with the rules of logical syntax of the identity symbol in the proposition " $2 \times 2$ and 4 are identical" and is capable of, and in this case is, signifying (as identity). If the rules of the identity symbol are intended, then the sign "identical" is used in contravention of logical syntax in the combination "Socrates is identical" and is incapable of signifying. In that case, the sign "Socrates is identical" cannot be thought in accordance with the rules of logical syntax so as to express a sense, and is thus nonsensical. It is in this way that the rules of logical syntax govern the use (combination) of signs, or exclude nonsensical combinations of signs. (Note that a combination of signs is nonsensical not because it expresses nonsense, but because it fails to symbolize or to make any contribution to the expression of sense.)

The only way one can say that a symbol is used in accordance with the rules of logical syntax is in the trivial sense that any symbol must be used in accordance with logical syntax. For a symbol, as a sensecharacterising part of a proposition (TLP 3.31), is simply a sign used in accordance with logical syntax (and projected onto reality). There is no way that one can talk about using a symbol in contravention of the rules of logical syntax, because in that case the sign simply fails to become a symbol. Hence, the rules of logical syntax do not govern the combination of symbols but only signs. The notion considered by Diamond and Conant is therefore unacceptable by the Tractatus. The Tractatus adopts a notion of the contravention of logical syntax as the use of a sign in a way different from its intended rules of logical syntax. This explains why the contravention of logical syntax must produce nonsense, which is not substantial nonsense. Diamond and Conant cannot use a notion of the contravention of logical syntax, which 
entails substantial nonsense, to argue that there is no such thing as the contravention of logical syntax, for such a notion would not be adopted by the Tractatus in the first place.

Diamond and Conant's view is that, for the Tractatus, using a sign in a way not covered by the previously established uses must be using it in accordance with newly established uses. ${ }^{37}$ The onus of proof is actually on them. They need to argue that the Tractatus rejects the possibility of using a sign in contravention of previously established rules. (Note that there are two possible outcomes of intending a sign to be used in a way different from its previous uses. One is that it results in nonsense. Another is that it is used in accordance with newly introduced rules of logical syntax and thus becomes the sign of a different symbol. The resolutists reject the former.) I can find out from their writings only two arguments. One is that the contravention of logical syntax gives rise to substantial nonsense. This, however, was already refuted. Another argument is that the Tractatus says so in their crucial textual evidence TLP 5.4733:

Frege says that any legitimately constructed proposition must have a sense. And I say that any possible proposition is legitimately constructed, and, if it has no sense, that can only be because we have failed to give a meaning to some of its constituents. (Even if we think that we have done so.) Thus the reason why "Socrates is identical" says nothing is that we have not given any adjectival meaning to the word "identical". For when it appears as a sign for identity, it symbolizes in an entirely different way - the signifying relation is a different one - therefore the symbols also are entirely different in the two cases: the two symbols have only the sign in common, and that is an accident.

They read from TLP 5.4733 two points. First, no sentenceconstruction is illegitimate. It follows that there is no such thing as using signs in contravention of logical syntax. ${ }^{38}$ Second, the only way that the use of signs produces nonsense is the failure to assign meaning

37. See, for example, Diamond (2005, 78-79, 82, 84-87).

38. For this, Diamond $(2005,89)$ writes, "the view that no sentence-construction is illegitimately put together, that the rules establishing ways of using signs do not make any combination of signs into a would-be proposition a violation of what is allowed. If one reads 5.4733 in that way, it follows that Wittgenstein held that there is no such thing as a sentence which is nonsensical in virtue of use of the signs in it in ways which are excluded, because no ways of using signs are excluded". 
to them. ${ }^{39}$ TLP 5.4733 , however, does not say or imply these two points.

The first point is not there, because TLP 5.4733 only talks about a legitimately constructed sentence, and says that it is capable of signifying. TLP 5.4733 certainly does not support the view that no sentence construction is illegitimate, nor that there is no such a thing as using a sign in contravention of logical syntax. The second point is also not there.TLP 5.4733 says that a legitimately constructed sentence does not have a sense only because of the failure to assign meaning to some of its constituent signs. Of course, having no sense cannot be owing to the contravention of logical syntax because the sentence is well-formed (legitimately constructed). This, however, in no way excludes the possibility of an illegitimately constructed sentence. An ill-formed sentence is of course nonsensical because it does not provide a propositional context and thus, by what may be called "the context principle" in TLP 3.3, meaning cannot be assigned to its constituent signs. In fact, the failure to assign meaning is exactly because it contravenes the rules of logical syntax.

What is more, TLP 5.4733 contradicts Diamond and Conant's reading of it. To see this, consider the background against which TLP 5.4733 should be read. For the Tractatus, a sentence capable of expressing a sense must be well-formed (see, e.g., TLP 3.14). In general, a sign capable of signifying must be used in a propositional context, i.e., in accordance with the rules of logical syntax (TLP 3.3-3.311). Wittgenstein also stresses that a well-formed sentence is capable of expressing a sense, and this can be seen from TLP 4.5:

It now seems possible to give the most general propositional form: that is, to give a description of the propositions of any sign-language whatsoever in such a way that every possible sense can be expressed by a symbol satisfying the description, and every symbol satisfying the description can express a sense, provided that the meanings of the names are suitably chosen...

A symbol satisfying the description is one having the general propositional form, i.e., a well-formed sentence. A well-formed sentence is capable of expressing a sense, though it may not yet express a sense. In general, a sign used in accordance with the rules of logical syntax is capable of

39. For this, Conant $(2001,40)$ writes, "Wittgenstein says in this passage [i.e., TLP 5.4733 ] that the nonsensicality of the string is due not to an impermissible employment of a symbol, but rather to our failing to make a determination of meaning". 
signifying, and vice versa. The equivalence between well-formedness and capability of signifying is a crucial point that Wittgenstein wants to bring out in the Tractatus. It shows how the possibility of a signifying relation between language and the world can be found from the logical syntax of a language. TLP 5.4733 should be understood against this background.

Wittgenstein begins TLP 5.4733 by emphasising that a possible sentence may not have sense, but must be legitimately constructed, i.e., well-formed, and thus must be capable of signifying (a sense). In general, a possible sign is one which can become a symbol. When a sign becomes a symbol, it is used in accordance with the rules of logical syntax (or, in the case of a sentence, is legitimately constructed) and is capable of signifying. Thus, "[a] possible sign must also be able to signify" (TLP 5.473). ${ }^{40}$ If a possible sentence does not have a sense, it is only because meaning is yet to be assigned to the constituent signs. For example, the sign "identical" is used in "Socrates is identical" in a way different from its usual or previous uses (e.g., as the sign of identity), such that "Socrates is identical" may or may not make sense. When in the present case "identical" is used innovatively as the sign of an adjective, it is used in accordance with the rules of logical syntax governing an adjective and thus is a possible sign. "Socrates is identical" is then a possible sentence. The reason why "Socrates is identical" still does not have a sense is not because it, or "identical", is used in contravention of logical syntax, but because an adjectival meaning (the meaning of an adjective) is yet to be given to "identical".

Far from rejecting the possibility of the contravention of logical syntax, the last part of TLP 5.4733 shows that Wittgenstein is aware of such a possibility. His view is that, so far as "identical" is used as the sign of an adjective, it is used in accordance with the rules of logical syntax governing the uses of an adjectival sign. But when "identical" is intended to be used as the sign of identity (which is the sign of a different symbol), it contravenes the relevant rules of logical syntax. The result would be that "Socrates is identical" is nonsensical. (It would be as nonsensical as the sentence "the good is more or less identical than the beautiful" in TLP 4.003.) TLP 5.4733 clearly allows for the possibility of the contravention of logical syntax. Hence, Diamond and Conant's major textual evidence actually goes against

40. This is Ogden's translation.

(C) 2008 The Author. Journal compilation (C) 2008 Blackwell Publishing Ltd. 
their implausible view that, for the Tractatus, there cannot be such a thing as using a sign in contravention of logical syntax.

One can now see that what is right about the second basic feature (i.e., that the Tractatus does not advance any theory of meaning specifying the conditions of sense) is not essential to the resolute reading (as the standard interpretations also hold), and what is essential to it (i.e., that there is no such thing as using signs in contravention of logical syntax) is wrong.

The two basic features, which are either not distinct from the standard interpretations or incorrect, do not characterise the resolute reading. What really do characterise it, I think, are the other two major claims of the resolute reading. One is the claim that all the sentences of the Tractatus, except those few serving as "the frame" or reading instructions, are nonsensical. Another is the more important claim that the purpose of the Tractatus is not to show any unsayable insights, but merely to liberate nonsense utterers from nonsense via elucidation by the nonsensical non-frame Tractarian sentences, and this is what seeing the world aright consists in. I shall examine these two contentions before turning to introduce what I think is a correct way of reading the Tractatus.

The claim that all the sentences of the Tractatus except those forming the frame are nonsensical is connected with the fact that the resolute reading claims to be taking TLP 6.54 seriously. But TLP 6.54 only says that the sentences of the Tractatus serving as elucidations are nonsensical. It does not say that the significant propositions of the Tractatus constitute the frame or reading instructions. And there does not seem to be any other textual evidence. In fact, the claim seems to be false. For one can easily find sentences from the Tractatus, like "Darwin's theory has no more to do with philosophy than any other hypothesis in natural science" (TLP 4.1122), which are obviously significant propositions but not reading instructions. Moreover, Diamond and Conant are not consistent in holding their positions. In several of their papers, as we have already seen, they use TLP 5.4733 to argue that there is no such a thing as the contravention of logical syntax. What is the status of TLP 5.4733? It cannot belong to the frame because it is not a reading instruction. It cannot be nonsensical 
because no nonsensical sentence can convey the message that "no sentence-construction is illegitimately constructed" (Diamond 2005, 89). The only possible move left for the resolutists is to concede this and to take TLP 5.4733 as a significant proposition but not a reading instruction, hence the inconsistency.

Let me now turn to the more important claim that the purpose of the Tractatus is merely to liberate nonsense utterers from nonsense via elucidation by the nonsensical non-frame Tractarian sentences. Diamond and Conant cannot seek help from significant propositions (as they are ignorant of the view that what the nonsensical sentences are intended to say can be shown by significant propositions), but only from nonsensical sentences themselves. This explains why Conant $(2000,196)$ says, "the aim of the Tractarian elucidation is to reveal (through the employment of mere nonsense) that what appears to be substantial nonsense is mere nonsense" (emphasis mine). The purpose of the Tractatus is to free one from the grip of substantial nonsense. In a way, the standard interpretations' view of recognising the sentences referred to in TLP 6.54 as nonsensical, so as to see that what they appear to be saying cannot be said, but is shown by significant propositions, is also liberating readers from nonsense. But this is not what Diamond and Conant mean. Their point is that liberating readers from nonsense is already the final consequence. ${ }^{41}$ Any talk in addition to this about showing something that cannot be said is out of the question. But there is no textual evidence supporting their view. They then appeal to the notions of elucidation and imagination, and thus appear to be offering such evidence. This, however, is not the case. To have a clearer look at this, I shall consider Diamond's particular version in detail.

In Diamond's version, she makes use of the notion of elucidation, and draws our attention to the fact that, TLP 6.54 says, the sentences of the Tractatus serve as elucidations in the way that "anyone who understands me eventually recognises them as nonsensical".

You are to understand not the propositions but the author... The Tractatus is a book that understands its own departure from the only strictly correct method to lie in its understanding of those who utter

41. For example, Conant $(2001,59)$ says, "[t]he sign that one of the sentences of the Tractatus has achieved its elucidatory purpose comes when the reader's phenomenology of having understood something determinate by the form of words in question is suddenly shattered". 
nonsense, and that demands exactly that understanding from its own readers.

So my claim now is that we cannot see how we are supposed to read the remarks on ethics in the Tractatus without seeing how Wittgenstein thought of its philosophical method, and crucial to that is his conception of what it is to understand a person who utters nonsense. What is it then to understand a person who talks nonsense? (Diamond 2001, 156; emphasis mine)

The key is to take the word "me" in TLP 6.54 to refer to a person who utters nonsense. What is important is to understand the utterer of those sentences and not the sentences themselves. To understand someone who talks nonsense is to "enter imaginatively the taking of that nonsense for sense" (Diamond 2001, 157). The activity of imagination is presupposed in the kind of elucidation served by the nonsensical Tractarian sentences. They elucidate by invoking the imagination of taking nonsense for sense by a nonsense utterer "who is in the grip of the illusion that there is philosophy in the traditional sense" (Diamond $2001,160)$ so as to lead the nonsense utterer out of it. ${ }^{42}$

The word "me" in TLP 6.54 obviously refers to Wittgenstein - the author of the Tractatus. But Diamond takes it to refer to anyone who utters nonsense, and is in the grip of the illusion that there is philosophy in the traditional sense. However, to take "me" to mean any such nonsense utterer is not a natural way of reading TLP 6.54. For what Wittgenstein wants to say in TLP 6.54 is clearly not an invitation to people to understand nonsense utterers like him, but that anyone who understands the author would be able to recognise his sentences as nonsensical. Why is anyone who understands him able to do that? It is because immediately before TLP 6.54 , he, i.e., the author, has just taught us the correct method in philosophy:

The correct method in philosophy would really be the following: to say nothing except what can be said ... and then, whenever someone else wanted to say something metaphysical, to demonstrate to him that he had failed to give a meaning to certain signs in his propositions ... (TLP 6.53)

One who understands him understands the correct method, and one who understands the method is capable of recognising his sentences as

42. Conant also introduces the notion of imagination into that of the Tractarian elucidation. The Tractarian sentences elucidate by invoking the imagination of something appearing to be substantially significant which is only later to be exposed as mere nonsense, i.e., by revealing that what appears to be substantial nonsense is mere nonsense (Conant 2000, 196-197). 
nonsensical. The recognition of the nonsensicality of the sentences, according to TLP 6.54, is what the elucidation of the sentences consists in and what, by means of this, enables one to see the world aright.

Diamond's emphasis on the use of the word "me" in TLP 6.53 does not support her view that the nonsense utterer is invited to enter imaginatively into nonsense so as to be liberated from it. But is this the purpose of the Tractatus? Diamond's attention to the preface only focuses on what Wittgenstein calls "the aim" and "the whole sense" of the book. But, as already pointed out by some commentators, ${ }^{43} \mathrm{Witt}-$ genstein also emphasizes in the preface that the "value" of the Tractatus, if any, consists in two things, one of which is that "thoughts are expressed in it", where "the truth of the thoughts that are here communicated" seems to him to be "unassailable and definite". ${ }^{44}$ The Tractatus will be understood only by someone who already has the thoughts, or similar thoughts, expressed in it. The communication of thoughts by means of the Tractatus, of which Wittgenstein himself is well aware, is not necessarily done via sentences contained in the book. It is to be done, as I shall argue, by directing readers to see for themselves something that is shown by significant propositions. To understand a thought is to grasp the sense shown by the relevant proposition (TLP 4, 4.02 and 4.022). Grasping those "true" thoughts is intimately connected to his effort in the Tractatus to dissolve the problems of philosophy. It is also related to his view of seeing the world aright after recognising the nonsensicality of those Tractarian elucidations (TLP 6.54). Contrary to what Diamond thinks, Wittgenstein is in effect declaring in the preface that the Tractatus is trying to help its readers to see unsayable insights.

In fact, Wittgenstein does not think dissolving philosophical utterances is all that one can achieve by philosophical activity, nor is it the ultimate aim. He stated in the preface that the whole sense of the Tractatus is that "what can be said at all can be said clearly, and what we cannot talk about we must pass over in silence" (TLP, p. 3), and closed the Tractatus with the words "what we cannot speak about we must pass over in silence" (TLP 7). The "pass over" here indicates that, when

43. See, e.g., Reid (1998, 97-151; especially, 100) and Hacker (2000, 108-109).

44. By saying that the truth of the thoughts seems to be unassailable and definite, Wittgenstein seems to be using the word "truth" loosely. This is like his use of it in "provides the key to the problem, how much truth there is in solipsism" in TLP 5.62, or similar to the "shifting use" of the word "object" in TLP 4.123. 
philosophical utterances and Tractarian elucidations are recognised as nonsensical, it is not the case that there is nothing left but, rather, that there are things which cannot be said and thus should be left aside silently. He also says in the preface that the value of the Tractatus consists in two things, one of which is that "it shows how little is achieved when these problems [the problems of philosophy] are solved" (TLP, p. 3). He does not say that it shows nothing but that how "little" is achieved. It is also well known that he says, when someone has used and thrown away his nonsensical elucidatory sentences, "he will see the world aright" (TLP 6.53). Immediately before stating the correct method in philosophy and explaining how his sentences elucidate by being recognised as nonsensical in TLP 6.53-6.54, he talks about the problem of life and says,

The solution of the problem of life is seen in the vanishing of this problem.

(Is not this the reason why men to whom after long doubting the sense of life became clear, could not then say wherein this sense consisted?)

There is indeed the inexpressible. This shows itself; it is the mystical.

(TLP 6.521-6.522) $)^{45}$

Hence, the recognition of the nonsensicality of philosophical utterances and of the Tractarian elucidations helps one see something which cannot be said but only shown (TLP 4.1212). With this, I shall suggest a way of understanding the Tractatus correctly.

The Tractatus mainly consists of nonsensical elucidations. But how can nonsensical sentences shed light on the nature of language and logic, and the correct method in philosophy? How are they related to philosophy and philosophical utterances? One thing that the resolutists fail to see is that although nonsensical sentences neither show nor say anything, some of them may be employed to direct one to see something that is shown by significant propositions. There are in fact two different roles nonsensical sentences may play. One is that they are presented as philosophical utterances as if they were saying something

45. Ogden's translation is used here. 
profound. Another is that they are employed as elucidations to help one to see something that cannot be said but shown by significant propositions. I shall first explain how the Tractarian elucidations fulfill the second role.

Let me consider how a nonsensical elucidation functions, and see what logical inference and proof in the Tractatus are.

It is impossible, however, to assert by means of propositions that such internal properties and relations obtain: rather, this makes itself manifest [zeigt . . . sich; shows itself] in the propositions that represent the relevant states of affairs and are concerned with the relevant objects. (TLP 4.122)

Thus one proposition " $f a$ " shows that the object a occurs in its sense, two propositions " $f a$ " and " $g a$ " show that the same object is mentioned in both of them. If two propositions contradict one another, then their structure shows it; the same is true if one of them follows from the other. And so on. (TLP 4.1211)

"fa" shows that the object a occurs in its sense. What shows is the proposition "fa" and not the nonsensical sentence "a occurs in the sense of ' $\mathrm{fa}$ " ". A nonsensical sentence like "a occurs in the sense of ' $\mathrm{fa}$ '" is elucidatory not because it says or shows anything (which it cannot), but via it being recognised as nonsensical.

One who understands Wittgenstein and thus his method in philosophy (TLP 6.53) can see from the fact that connecting those familiar words in such a manner produces a nonsensical sentence, and what is being attempted to be said by the nonsensical sentence cannot be said (nor be shown by the nonsensical sentence), but is shown by significant propositions saying something else. For example, what one may attempt to say by employing the nonsensical sentence "a occurs in the sense of "fa' " is shown by the significant proposition "fa". What the proposition "fa" shows must be passed over in silence because what it shows is not, and cannot be, spoken about. Nevertheless, "fa" does say something, though what it says is not what it shows. It says something else, namely, that "fa". It is in this way that what a proposition shows is passed over (TLP 6.54) silently in it saying something else. This is how, I believe, TLP 7 ("What we cannot speak about we must pass over in silence") should be understood.

A sentence like " 'q' follows from 'p' " is also nonsensical. It may serve as an elucidation, which directs one to see that what it appears to be saying is shown by the structure of the significant propositions "p" and "q". The combination of the significant propositions " $p$ " and 
"q" in " 'q" follows from 'p" " makes the sentence appear to be saying something. But this is just appearance. It is nonsensical. Recognition of this leads one to see that the internal logical structure of "p" and "q" is what matters here. In general, "[w]hen the truth of one proposition follows from the truth of others, we can see this from the structure of the proposition" (TLP 5.13). In some cases, one can see the logical structure by merely inspecting the propositions "p" and "q" themselves (TLP 6.122). In other cases, checking whether " $p \supset q$ " is tautological would be helpful. The tautology " $p \supset q$ " is senseless (TLP 4.461), but what it shows is also shown by the significant propositions " $p$ " and " $q$ ", or their internal logical relation (TLP 6.2).

The Tractatus has no hesitation in talking about proofs in logic (TLP $5.132,6.12-6.1262)$. Wittgenstein's idea is indeed the clear one that a proof in logic is a demonstration of the internal logical structure of significant propositions, which nonsensical elucidations like " 'q' follows from ' $\mathrm{p}$ " ", or senseless tautological elucidations like " $\mathrm{p} \supset \mathrm{q}$ ", would help or direct one to see. There are also other proofs like the proof of the existence of the general propositional form (TLP 4.5), the proof of the picture thesis that "[a] proposition is a picture of reality" (TLP 4.01), the proofs of the Grundgedanke (TLP 4.0312), etc. Proofs in the Tractatus are, one may say, the exploration of the rules of syntax of signs. (The fact that the proofs in the Tractatus employ nonsensical elucidations to direct one to see something that is shown by significant propositions does not mean that their tasks are easy. ${ }^{46}$ They are not cheap claims but results from hard-won battles. ${ }^{47}$ )

These views about the nature of language and logic are among the thoughts that Wittgenstein states in the preface to have been expressed in the book. The Tractatus also contains various "theses" (or "pseudo-

46. In a letter to Lady Ottoline Morrell, Russell writes about Wittgenstein, "I told him he ought not simply to state what he thinks true, but to give arguments for it, but he said arguments spoil its beauty, and that he would feel as if he was dirtying a flower with muddy hands" (quoted in Blackwell 1981, 8). This suggests that Wittgenstein is well aware of and deliberately leaves a lot of argument details and steps. The task of finding out those details is not an easy one. I would like to thank Laurence Goldstein for drawing my attention to this point. For his views on this matter, see Goldstein (2004, 158-9).

47. For example, I have explained how Wittgenstein in the Tractatus argues for the Grundgedanke in Cheung (1999), the existence of the sole logical constant in Cheung (2000), the picture thesis in Cheung (2003), the truth-functionality of logical necessity in Cheung (2004), and the existence of the most general propositional form and the unity of language and logic in Cheung (2006). 
theses"), like the picture thesis. These "theses", being nonsensical, cannot convey anything about the nature of language and logic. However, recognising their nonsensicality helps one see something about the nature of language and logic shown by significant propositions. (This is similar to the fact that recognising that tautologies say nothing directs one to see the logic of the constituent propositions.) He seems to think that what those nonsensical sentences attempt to say were supposed to be about the conditions of saying (i.e., logic), and so must be there whenever we are saying something significant. The nonsensical sentences themselves neither say nor show anything. Rather, what they appear to be saying, i.e., the conditions of saying, reside in significant propositions saying something else.

Nonsensical sentences may also be posed as philosophical utterances. Philosophy is an activity aiming at dissolving philosophical utterances, which is achieved by the clarification of propositions, i.e., the expressions of thoughts (TLP 4.112). The task of philosophy is "to make thoughts clear and to give them sharp boundaries" (TLP 4.112), or to present "clearly what can be said" (TLP 4.115), by setting limits to language (TLP 4.113-4.116). Drawing a limit to language is intimately related to the establishment of the correct method in philosophy. How can the "theses" in the Tractatus contribute to achieving this? The "thesis" that plays the crucial role here is the important view of the equivalence between using signs in accordance with the rules of logical syntax and the capability of signifying in TLP 5.4733. To see this, note that language is the totality of propositions (TLP 4.001). The limits of propositions, which constitute the limit of language, ${ }^{48}$ however, do not belong to language (TLP 6.43) ${ }^{49}$ but are fixed by the totality of propositions (TLP 4.51).

It appears that one way to draw a limit to language is to give the totality of propositions (and thus fix their limits). But the Tractatus does not and cannot give such totality because not even the totality of elementary propositions can be given (TLP 5.55-5.551). What it does

\footnotetext{
48. The Tractatus sometimes refers to drawing "a limit" to language (e.g., in TLP, p. 3), and sometimes to setting "limits" to language (e.g., in TLP 4.113-4.116). I take the former as referring to the limits of language collectively.

49. One can see from TLP 5.6 ("The limits of my language mean the limits of my world") and TLP 6.43 ("[i]f the good or bad exercise of the will does alter the world, it can alter only the limits of the world, not the facts - not what can be expressed by means of language") that Wittgenstein does not think the limits of language belong to language.
} 
do is to give a description of the general form of a proposition, which is the general rule referred to indirectly in TLP 4.5 and directly but in a more abstract manner in TLP 4.014. I shall not explain the details of Wittgenstein's argument here as I have done so elsewhere. ${ }^{50}$ Nevertheless, I want to point out that the Tractatus sees tautologies and contradictions not as genuine propositions (and thus not belonging to language) but as the limiting cases, or simply the limits, of propositions (TLP 4.466, 5.143). Since propositions and logical propositions (tautologies and contradictions) are products of the same general rule of language, logic and language are unified.Those lying within the limit of language are propositions, those on it tautologies and contradictions, and those outside it nonsense. Tautologies and contradictions constitute the limit of language and yet are fixed by the totality of propositions.

Logical syntax determines whether a sentence lies within, on or outside the limit of language ${ }^{51}$ This is connected to the Tractatus' view that a sign used in accordance with the rules of logical syntax is capable of signifying, and vice versa. The view is what Wittgenstein tries to bring out in TLP 5.4733, and the discussion of the most general propositional form in TLP 4.5 is based on it. What is more important here is its characterisation of the notion of drawing a limit to language. First, a sentence in which signs are used in contravention of the rules of logical syntax lies outside the limit. The sentence is in this case nonsensical because its constituent signs cannot signify, i.e., meaning cannot be assigned to them. The converse also holds. Second, a sentence whose constituent signs are used in accordance with the rules of logical syntax lies within or on the limit. It is either capable of expressing a sense (though it may not yet express a sense) and thus lies within the limit, or cannot express a sense and thus lies on the limit. The latter is a logical proposition (tautology or contradiction), and it lacks sense (TLP 4.461). A logical proposition, however, is still wellformed. The constituent names of its constituent elementary propo-

50. See Cheung (2006).

51. The fact that the Tractatus understands logical syntax in this way can be seen from TLP 3.344 and 6.124. TLP 6.124 says that "[i]f we know the logical syntax of any sign-language, then we have already been given all the propositions of logic". Logical syntax gives prominence to the general rule governing the formation of logical propositions. TLP 3.344 says that "[w] hat signifies in a symbol is what is common to all symbols that the rules of logical syntax allow us to substitute for it". Logical syntax also gives prominence to the general rule of language which governs the formation of symbols capable of signifying. For the Tractatus, language and logic are unified via logical syntax. 
sitions are used in accordance with the rules of logical syntax and thus are capable of signifying, or denoting, objects. But the fact that a logical proposition admits all situations (in the case of a tautology) or none (in the case of a contradiction) means that the signifying relations, or representational relations, cancel one another (TLP 4.462). It is therefore senseless, though not nonsensical.

The important view of the equivalence between using signs in accordance with the rules of logical syntax and the capability of signifying gives rise to what the Tractatus regards as the strictly correct method in philosophy:

The correct method in philosophy would really be the following: to say nothing except what can be said, i.e., propositions of natural science - i.e., something that has nothing to do with philosophy and then, whenever someone else wanted to say something metaphysical, to demonstrate to him that he had failed to give a meaning to certain signs in his propositions ... this method would be the only strictly correct one. (TLP 6.53)

If meaning has not been given to some constituent signs of a sentence, then the sentence does not have a sense. It may still be significant if suitable meaning is assigned to the constituent signs. But it must be nonsensical if meaning cannot be assigned to the constituent signs because, in this case, it contravenes the rules of logical syntax. When one poses a nonsensical sentence as a philosophical proposition, it is the second case that is at stake. To dissolve a philosophical utterance, the correct method in philosophy consists in pointing out the meaninglessness of a certain sign in the relevant sentence.

\section{VI}

In TLP 6.44-6.45, Wittgenstein talks about a few things that are mystical, one of which is the existence of the world (as a limited whole). For at least some of us, whenever we contemplate the existence of the world, we seem to be seized by a sense of wonder. Some may subsequently utter sentences like "The world exists" (TLP 6.44), "I feel the world as a limited whole" (TLP 6.45) and even the solipsist's claim that "I am my world" (TLP 5.63). In "A Lecture on Ethics", he mentions three experiences having what he calls "absolute value". One is the experience that he has when he wonders at the existence of the world (LE, p. 41). Someone may try to put this into 
words and utter, say, "The world exists". "The world exists" here is a philosophical utterance. It is posed as if it says something profound. Even for Tractarian elucidations like "A proposition is a picture of reality", someone may find the relevant thought perplexing and mistakenly present the sentence as if it says something profound. (The Tractatus of course does not present it in this way, but rather employs it as an elucidation.) In the lectures Wittgenstein delivered in the 1930s, he considered the puzzle of what a proposition one encounters is when one philosophises. "What is a proposition?" is posed there as if it were asking something about the nature of language. In that case, the sentence is also a philosophical utterance.

People utter such philosophical utterances because they want to say or respond to what they have found perplexing. Wittgenstein, as the author of "A Lecture on Ethics", would say that sentences like "The world exists" are nonsensical not because one has not yet found the correct expression, but that their nonsensicality is their very essence (LE, p. 44). In the Tractatus, he hints at something very similar. He thinks that the reason why those people think they can say something about what they found perplexing is because of the misunderstanding of the logic of language (TLP, p. 3, 4.003). What contribute to the misunderstanding are the tacit conventions of ordinary language, which in many cases make the expressions of thoughts (propositions) themselves disguise thoughts (TLP 4.022). Philosophical utterances are actually products of using signs in contravention of the logic of language, i.e., logical syntax, and thus must be nonsensical. They are not to be answered.They are to be dissolved by pointing out that the relevant propositions and questions are nonsensical (TLP 4.003).

Wittgenstein also says in the preface that the Tractatus is not a textbook, and that it will be understood only by someone who already has the thoughts or similar thoughts expressed in it. He says in TLP 6.54 that whoever understands him eventually recognises his elucidations as nonsensical. This presumably also applies to the case of philosophical utterances. Philosophy therefore does not consist of philosophical propositions but is an activity (TLP 4.112). ${ }^{53}$ It is an activity which employs the correct method to analyse those philosophical utterances. He would not do that on one's behalf, nor is that necessarily done via

52. See WCL, p. 1, pp. 21-22, pp. 42-44.

53. I use Ogden's translation of "Philosophische Sätze" in TLP 4.112 here, instead of Pears and McGuinness' translation "doctrines". 
sentences contained in the Tractatus. One has to engage in the activity of philosophy by oneself. By doing this, one would not just recognise those philosophical utterances as nonsensical, but also be directed to see that what the utterers attempt to say by means of them is already shown by significant propositions. This is also what seeing the world aright consists in.

It is now clear why Wittgenstein sums up the whole sense of the Tractatus in the sentence, "What can be said at all can be said clearly, and what we cannot talk about we must pass over in silence". The idea is that in saying what we can say clearly, we also see what cannot be said, which is shown by the expression of what we say. We pass over those nonsensical elucidations and philosophical utterances (which constitute the ladder to be thrown away) and see that what they appear to be saying, but cannot be said, is shown by our saying something else. This explains something that Wittgenstein says in his letter to von Ficker:

I wanted to write that my work consists of two parts: of the one which is here, and of everything which I have not written. And precisely this second part is the important one. For the Ethical is delimited from within, as it were, by my book; and I'm convinced that, strictly speaking, it can ONLY be delimited in this way. In brief, I think: All if that which many are babbling today, I have defined in my book by remaining silent about it. Therefore the book will, unless I'm quite wrong, have much to say which you want to say yourself, but perhaps you won't notice that it is said in it. For the time being, I'd recommend that you read the foreword and the conclusion since these express the point most directly. (LLF, 94-95)

He remains silent about what is shown by sentences saying something else. That is why "the book will . . have much to say which you want to say yourself, but perhaps you won't notice that it is said in it". The above also explains what Wittgenstein is hinting at when he says to Paul Engelmann about a poem by Uhland:

And this is how it is: if only you do not try to utter what is unutterable then nothing gets lost. But the unutterable will be unutterably - contained in what has been uttered $!^{54}$

Wittgenstein, as it is well known, later discovers what he calls "grave mistakes" of the Tractatus (PI, p. x). I am not able to discuss here what those grave mistakes are or how much of his early philosophy in the

54. Quoted by Monk (1991, 151). 
Tractatus he renounced. I just want to say that the Tractatus is a beautiful work, and that if it is a failure it is a glorious failure. The Tractatus is not as what the resolutists think. Its main purpose is not merely to liberate the nonsense utterer from nonsense. It aims to help one recognise the nonsensicality of its elucidations and to introduce the correct method in philosophy so as to dissolve philosophical utterances and to see unsayable insights about the world, language and logic, which are shown by significant propositions saying something else. It has flaws, but its author tries hard to ingeniously demonstrate how he thinks its aims can be achieved. ${ }^{55}$

\section{References}

Anscombe, G. E. M. (1971). An Introduction to Wittgenstein's Tractatus. Philadelphia: University of Pennsylvania Press.

Black, M. (1964). A Companion to Wittgenstein's Tractatus. Ithaca: Cornell University Press.

Blackwell, K. (1981). "The Early Wittgenstein and the Middle Russell”. In I. Block (eds.), Perspectives on the Philosophy of Wittgenstein. Oxford: Basil Blackwell, pp. 1-30.

Cheung, L. K. C. (1999). "The Proofs of the Grundgedanke in Wittgenstein's Tractatus." Synthese 120 (3): 395-410.

- (2000). "The Tractarian Operation N and Expressive Completeness." Synthese 123 (2): 247-261.

- (2003). "Language as a Geometry in Wittgenstein's Tractatus."

In W. Löffler and P. Weingartner (eds.), Knowledge and Belief: Papers

of the 26th International Wittgenstein Symposium. Austria: Austrian Ludwig Wittgenstein Society, pp. 91-93.

- (2004). "Showing, Analysis and the Truth-Functionality of

Logical Necessity in Wittgenstein's Tractatus." Synthese 139 (1): 81-105.

- (2006). "The Unity of Language and Logic in Wittgenstein's

Tractatus." Philosophical Investigations 29 (1): 22-50.

55. Earlier drafts of this paper have been read at an international conference at Beijing in 2002 and at a seminar at the University of Sussex in 2003. I would like to thank the audience there for their comments. Peter Hacker, Laurence Goldstein and Michael Morris read different versions of this paper at different stages of its composition. I would like to thank them, as well as the editor of Philosophical Investigations and a reviewer, for their comments and suggestions. 
Conant, J. (1989). "Must We Show What We Cannot Say?” In R. Fleming and M. Payne (eds.) The Senses of Stanley Cavell. Lewisburg: Bucknell University Press, pp. 242-283.

- (2000). "Elucidation and Nonsense in Frege and Early Wittgenstein." In A. Crary and R. Read (eds.), The New Wittgenstein. London: Routledge, pp. 149-173.

. (2001). "Two Conceptions of Die Überwindung der Metaphysik: Carnap and Early Wittgenstein." In T. McCarthy and S. C. Stidd (eds.), Wittgenstein in America. Oxford: Clarendon, pp. 1361.

. (2002). "The Method of the Tractatus." In E. H. Reck (ed.),

From Frege to Wittgenstein. Oxford: OUP, pp. 374-462. . (2007). "Mild Mono-Wittgensteinianism." In A. Crary (ed.), Wittgenstein and the Moral Life: Essays in Honor of Cora Diamond. Cambridge: MIT Press, pp. 31-142.

Conant, J. and C. Diamond, (2004). "On Reading the Tractatus Resolutely: Reply to Meredith Williams and Peter Sullivan." In H. Kolbel and D. Weiss (eds.), Wittgenstein's Lasting Significance. London: Routledge, pp. 46-99.

Crary, A. and R. Read, eds. (2000). The New Wittgenstein. London: Routledge.

Diamond, C. (1991a). The Realist Spirit. Cambridge: MIT Press. . (1991b). "Throwing Away the Ladder: How to Read the Tractatus." In C. Diamond (ed.), The Realist Spirit. Cambridge: MIT Press, pp. 179-204.

. (1997). "Realism and Resolution: Reply to Warren Goldfarb and Sabina Lovibond". Journal of Philosophical Research 22: 75-86. . (2001). "Ethics, Imagination and the Method of Wittgenstein's Tractatus." In A. Crary and R. Read (eds.), The New Wittgenstein. London: Routledge, pp. 149-173.

. (2005). "Logical Syntax in Wittgenstein's Tractatus." Philosophical Quarterly 55 (218): 78-89.

Goldfarb, W. (1997). "Metaphysics and Nonsense: On Cora Diamond's the Realist Spirit". Journal of Philosophical Research 22: 57-73. Goldstein, L. (2004). "Wittgenstein as Soil.” In M. Kolbel and B. Weiss (eds.), Wittgenstein's Lasting Significance. London: Routledge, pp. 148-178.

Hacker, P. M. S. (1986). Insight and Illusion, revised edition. Oxford: Clarendon. 
. (2000). "Was He Trying to Whistle It?" In A. Crary and R.

Read (eds.), The New Wittgenstein. London: Routledge, pp. 253288.

. (2001). "Philosophy." In H-J. Glock (ed.), Wittgenstein: A Critical Reader. Oxford: Blackwell, pp. 322-347.

-. (2003). "Wittgenstein, Carnap and the New American Wittgensteinian.” The Philosophical Quarterly 53/210: 1-23.

Kremer, M. (2001). "The Purpose of Tractarian Nonsense.” Noûs 35 (1): 39-73.

McGinn, M. (1999). "Between Metaphysics and Nonsense: Elucidation in Wittgenstein's Tractatus." The Philosophical Quarterly 49 (197): 491-513.

Monk, R. (1991). Ludwig Wittgenstein: The Duty of a Genius. London: Vintage.

Mounce, H. O. (2003). "Reply to Read and Deans." Philosophical Investigations 26 (3): 269-270.

Read, R. and R. Deans (2003). "Nothing is Shown": A 'Resolute' Response to Mounce, Emiliani, Koethe and Vilhauer." Philosophical Investigations 26 (3): 239-268.

Reid, L. (1998). "Wittgenstein's Ladder:The Tractatus and Nonsense." Philosophical Investigations 21/2: 97-151.

Ricketts, T. (1996). "Picture, Logic, and the Limits of Sense in the Tractatus." In H. Sluga and D. Stern (eds.), The Cambridge Companion to Wittgenstein. Cambridge: CUP, pp. 59-99.

Sullivan, P. (2002). "On Trying to be Resolute: A Response to Kremer on the Tractatus." European Journal of Philosophy 10 (1): 43-78.

Wittgenstein, L. [TLP] (1974). Tractatus Logico-Philosophicus, D. F. Pears and B. F. McGuinness, trans. London: RKP.

- [TLP] (1981). Tractatus Logico-Philosophicus, C. K. Ogden, trans. London: RKP.

- [BB] (1958). The Blue and Brown Books. Oxford: Basil Blackwell.

- [NB] (1979). Notebooks 1914-1916, 2nd edition, G. H. von Wright and G. E. M. Anscombe, eds. G. E. M. Anscombe, trans. Oxford: Basil Blackwell.

- [WLC] (1980). Wittgenstein's Lectures Cambridge 1930-1932, D. Lee, ed. Oxford: Basil Blackwell.

- [PO] (1993a). Philosophical Occasions. Indiana: Hackett, pp. 1912-1951. 
[LE] (1993b). "A Lecture on Ethics.” Philosophical Occasions. Indiana: Hackett, pp. 36-44.

[LLF] (1996). "Letters to Ludwig von Ficker." In C. G. Luckhardt (ed.), Wittgenstein: Sources and Perspectives. London: Routledge, pp. 82-98.

. [PI] (2001). Philosophical Investigations, 3rd edition, G. E. M. Anscombe, trans. Oxford: Blackwell.

Department of Religion and Philosophy

Hong Kong Baptist University

Kowloon Tong

Hong Kong

kccheung@hkbu.edu.hk 